\title{
Few fishy facts found in climate report
}

\section{Dutch investigation supports key warnings from the IPCC's most recent assessment.}

How much of the Netherlands lies below sea level? It seems an innocuous question - but it sparked a major review of the work of the Intergovernmental Panel on Climate Change (IPCC).

The investigation, commissioned by the Dutch government, focused on the contribution of Working Group II - on impacts, adaptation and vulnerability - to the IPCC's Fourth Assessment Report ${ }^{1}$. The Dutch report's conclusions ${ }^{2}$, released on 5 July, highlight a number of mistakes - some trivial, others more egregious - and suggest ways to minimize errors in the future. But they also confirm the IPCC report's core message: that global warming poses substantial risks to societies and ecosystems on all continents.

"By and large, the IPCC has delivered a formidable summary of the current state of knowledge," says Maarten Hajer, director of the Netherlands Environmental Assessment Agency (PBL) in Bilthoven, which carried out the investigation. "It's not flawless but it is the best we have, and the best we can aim for is to further improve it."

The inquiry was triggered by widespread media coverage of two errors in the IPCC report: claims that all Himalayan glaciers might melt by 2035 (glaciologists say they are unlikely to melt so quickly) and that more than $55 \%$ of the Netherlands lies below sea level (the real figure is 26\%). In April, the Dutch minister for the environment at the time, Jacqueline Cramer, commissioned the PBL to reassess the reliability of the IPCC's regional projections. The PBL then double-checked with the IPCC's coordinating lead authors all statements in relevant chapters that seemed unclear, unfounded or inconsistent.

This process has uncovered nothing that would undermine the IPCC's main conclusions, or the Dutch's government's plans for adapting to climate impacts, including sealevel rise, says Hajer. Ironically, the Dutch sea-level error derived from the PBL's own figures, which has caused embarrassment. "My authors were certainly bemused to find themselves interviewed by PBL about their work when actually it was PBL that provided the wrong information which caused the furore in the first place," says Martin Parry, a visiting professor at Imperial College London and

\section{former co-chair of Working Group II.}

In 32 projected regional impacts highlighted in the IPCC report's 'Summary for Policymakers', the PBL found only one factual error. The number of Africans projected to be exposed to water shortage due to climate change, stated as 75 million to 250 million people, should be 90 million to 220 million.

Elsewhere in the IPCC report, a predicted $50-60 \%$ decrease in the productivity of anchovy fisheries was erroneously derived from an unrelated study projecting a $50-60 \%$ decrease in extreme wind and ocean turbulence. Other errors include a handful of incorrect references, table titles and typos.

“'Sloppy' is the relevant word, sadly missing from the report, as it suggests that the errors are neither major flaws in the science nor intended to deceive the reader," says Leonard Smith, a statistician at the London School of Economics. "Many of the shortcomings noted could be spotted by scientific copy editors and research assistants."

The PBL review also criticizes some IPCC report statements as too generalized, citing the claim that freshwater availability will decrease "in all parts" of Asia. And it points out that the report did not highlight positive impacts of climate change, such as higher crop yields in some countries, in the summary for policy-makers.

The IPCC has already corrected many of the errors - including the anchovy prediction on its website. But some, including the number of people affected by water shortages in Africa, remain uncorrected, as the IPCC authors stand by their statements.

"I am glad the PBL has found them, but we don't agree with some of the details of individual points," says Parry. He also rejects criticisms of tone and emphasis. "If you have to summarize complex research in ten-word statements there will obviously be generalization," he says. "And when the main projected impacts are all negative, should we really have emphasized the trivial positive impacts as the PBL delicately implies?"

A parallel assessment of the IPCC's processes and procedures is currently being conducted by the Amsterdambased InterAcademy Council, composed of representatives of national academies of science from around the world. It is due to deliver its recommendations to the United Nations next month, and is likely to reinforce some of the suggestions made by the PBL review. For example, the Dutch panel says that the next IPCC assessment report should be more transparent about how climate-impact researchers arrive at their judgements and recommendations, and should invest more in fact-checking.

\section{Trust me, I'm an expert}

"I appreciate the importance of placing a clear emphasis on explaining how issues are framed and how conclusions are reached," says Chris Field, director of global ecology at the Carnegie Institution for Science in Stanford, California, who now co-chairs Working Group II. "I also see real value in the suggestion that funding for support staff for IPCC author teams could help insure careful quality checking of every statement."

"We will of course pay close attention to the PBL's recommendations for strengthening future reports," adds Rajendra Pachauri, chairman of the IPCC.

Such improvements are vital, not least because climate scientists are now very exposed to public scrutiny and criticism, says Leo Meyer, a project leader with the PBL and editor of the review. "The difficulty is to explain to the public how complex the problem of climate change is," he says. "Telling people 'Hey, I'm an expert - you need to trust me', is just no longer enough." Quirin Schiermeier

\footnotetext{
1. Parry, M. L. et al. (eds) Climate Change 2007: Impacts, Adaptation and Vulnerability. Contribution of Working Group II to the Fourth Assessment Report of the Intergovernmental Panel on Climate Change (Cambridge Univ. Press, 2007); available at go.nature.com/DGddCM

2. Assessing an IPCC Assessment: An Analysis of Statements on Projected Regional Impacts in the 2007 Report (Netherlands Environmental Assessment Agency, 2010); available at go.nature.com/wN2TxX
} 